\title{
Vitamin E for prevention of oxaliplatin-induced peripheral neuropathy: a pilot randomized clinical trial
}

\author{
Vitamina E na prevenção de neuropatia periférica induzida pela oxaliplatina: \\ estudo clínico piloto randomizado
}

\begin{abstract}
Samuel Oliveira de Afonseca', Felipe Melo Cruz", Daniel de Iracema Gomes Cubero"I', Andrea Thaumaturgo Lera', Fernanda Schindler", Marcia Okawara"', Luiz Fernando de Souza"', Nataly Pimentel Rodrigues "', Auro del Gigliov"
\end{abstract}

Department of Hematology and Oncology, Faculdade de Medicina do ABC (FMABC), Fundação ABC, Santo André, São Paulo, Brazil

'MD. Master's degree Student, Discipline of Hematology and Oncology, Faculdade de Medicina do ABC (FMABC), Santo André, São Paulo, Brazil.

"MD, MSc. Researcher and Head of the Residency Program, Discipline of Hematology and Oncology, Faculdade de Medicina do ABC (FMABC), Santo André, São Paulo, Brazil.

"'MD, MSc. Adjunct Professor, Discipline of Hematology and Oncology, Faculdade de Medicina do ABC (FMABC), Santo André, São Paulo, Brazil.

"MD. Resident Physician, Department of Internal Medicine, Faculdade de Medicina do ABC (FMABC), Santo André, São Paulo, Brazil.

vBSC. Pharmacist, Discipline of Hematology and Oncology, Faculdade de Medicina do ABC (FMABC), Santo André, São Paulo, Brazil.

"Medical Student, Faculdade de Medicina do ABC (FMABC), Santo André, São Paulo, Brazil.

VIMD, PhD. Titular Professor, Discipline of Hematology and Oncology, Faculdade de Medicina do ABC (FMABC), Santo André, São Paulo, Brazil.

\section{KEY WORDS:}

Drug therapy.

Vitamin E.

Peripheral nervous system diseases.

Prevention \& control.

Colorectal neoplasms.

Randomized controlled trials as topic.

\section{PALAVRAS-CHAVE:}

Quimioterapia.

Vitamina E.

Doenças do sistema nervoso periférico.

/Prevenção \& controle.

Neoplasias colorretais.

Ensaios clínicos controlados aleatórios como assunto.

\begin{abstract}
CONTEXT AND OBJECTIVE: Oxaliplatin is one of the chemotherapy regimens most used for treating colorectal cancer. One of the main limitations to its use is induction of peripheral neuropathy. Previous studies have shown that vitamin $\mathrm{E}$ can reduce the incidence of peripheral neuropathy by $50 \%$. This study aimed to assess the effectiveness of vitamin $E$ for prevention of oxaliplatin-induced peripheral neuropathy. DESIGN AND SETTING: Prospective, phase II, randomized pilot study developed at a university hospital in the Greater $A B C$ region.

METHODS: Patients were randomized five days before starting oxaliplatin treatment, to receive either vitamin E or placebo until the end of the chemotherapy regimen. The outcome was evaluated using the Common Terminology Criteria for Adverse Events (CTCAE), version 3, and specific gradation scales for oxaliplatin-induced peripheral neuropathy. Patients with colorectal and gastric cancer who had been scheduled to receive oxaliplatin-based chemotherapy were included. Both groups received calcium and magnesium supplementation before and after oxaliplatin infusions.

RESULTS: Eighteen patients were randomized to the vitamin E group and 16 to the placebo group. Cumulative incidence of $83 \%$ with peripheral neuropathy grades $1 / 2$ was observed in the vitamin E group, versus $68 \%$ in the placebo group $(P=0.45)$. A trend towards more diarrhea was observed among patients who received vitamin $E(55.6 \%$ vs. $18.8 \% ; P=0.06)$. There were no other significant differences in toxicity between the groups.
\end{abstract}

CONCLUSIONS: No significant decrease in the incidence of acute oxaliplatin-induced peripheral neuropathy was demonstrated through vitamin E use.

CLINICAL TRIAL REGISTRATION: NCT01523574.

\section{RESUMO}

CONTEXTO E OBJETIVO: A oxaliplatina é um dos quimioterápicos mais utilizados no tratamento do câncer colorretal, sendo a indução da neuropatia periférica (NP) uma das principais limitações para o seu uso. Trabalhos anteriores demonstraram que a vitamina E poderia reduzir a incidência dessa neuropatia em 50\%. Este estudo teve como objetivo avaliar a efetividade da vitamina E na prevenção da NP induzida pela oxaliplatina.

TIPO DE ESTUDO E LOCAL: Estudo piloto prospectivo e randomizado de fase Il desenvolvido em hospital universitário do Grande ABC.

MÉTODOS: Os pacientes foram randomizados para receber vitamina E ou placebo por cinco dias antes do início do tratamento com oxaliplatina e até o término do regime quimioterápico. O desfecho foi avaliado através dos Critérios Comuns de Toxicidade do Câncer versão 3 (CTCAE) e escalas específicas de gradação da NP induzida por oxaliplatina. Foram incluídos pacientes com câncer colorretal e gástrico programado para receber quimioterapia baseada em oxaliplatina. Ambos os grupos receberam suplementação de cálcio e magnésio antes e depois das infusões de oxaliplatina.

RESULTADOS: Dezoito pacientes foram randomizados para grupo da vitamina E e 16 para o grupo placebo. Observou-se incidência cumulativa de $83 \%$ das classes I/II de neuropatia periférica no grupo da vitamina $E$, contra $68 \%$ no grupo placebo $(P=0,45)$. Observou-se maior tendência à diarreia em pacientes que receberam vitamina $E(55,6 \%$ versus $18,8 \%, P=0,06)$. Não houve outras diferenças significativas quanto às toxicidades entre os grupos.

CONCLUSÃO: Não foi demonstrada diminuição significativa na incidência de NP aguda induzida por oxaliplatina com o uso de vitamina $E$.

REGISTRO DE ENSAIO CLÍNICO: NCT01523574. 


\section{INTRODUCTION}

Oxaliplatin is a frequently used medication that is part of many chemotherapy regimens for several gastrointestinal malignancies. It is an organoplatinum complex that can produce both interand intra-strand platinum-DNA crosslinks that, in turn, lead to inhibition of DNA replication and transcription. One of the most important toxic effects of oxaliplatin is induction of both acute and chronic peripheral neuropathy, which affects most patients treated with oxaliplatin. Peripheral neuropathy can be sufficiently severe to require treatment interruption. The mechanism of oxaliplatin-induced peripheral neuropathy seems to depend on a decrease in extracellular calcium levels, which may impair sodium influx and result in neuronal hyperexcitability. ${ }^{1-3}$

Vitamin E, which has antioxidant properties, has been evaluated with a view to preventing peripheral neuropathy in patients receiving cisplatin. Pace et al. ${ }^{4}$ evaluated 108 patients who were being treated with cisplatin and randomized them to receive vitamin E at $400 \mathrm{mg} /$ day or placebo. The incidence of neurotoxicity was significantly lower in the group treated with vitamin E $(5.9 \%$ versus 41.7\%; $\mathrm{P}<0.01$ ). Furthermore, Argyriou et al. demonstrated a $50 \%$ reduction in the incidence of peripheral neuropathy in patients undergoing cisplatin treatment who received $600 \mathrm{mg}$ of oral vitamin E per day, compared with those who received placebo. ${ }^{5}$ Argyriou et al. also confirmed these results in a later study. ${ }^{6}$

Antioxidant medications may play a role in decreasing the peripheral neurotoxicity of platinum-based chemotherapeutic regimens. Cascinu et al. showed that glutathione significantly decreased the rates of peripheral neuropathy induced by oxaliplatin. ${ }^{7}$ These authors demonstrated that, after 12 cycles of oxaliplatinbased chemotherapy, grade 2 to 4 neurotoxicity was observed in 3 out of 21 patients who received glutathione, versus 8 out of 19 who were randomized to receive placebo $(\mathrm{P}=0.004)$.

\section{OBJECTIVE}

To assess the effectiveness of vitamin $\mathrm{E}$ for prevention of oxaliplatin-induced acute peripheral neuropathy.

\section{METHODS}

This was a prospective, phase II, randomized study. From October 2009 to November 2010, we included patients at a university hospital located in the Greater ABC region of São Paulo. This study was approved by our Institutional Research Ethics Committee, and patients signed informed consent forms before inclusion in this study.

We included patients with an Eastern Cooperative Oncology Group (ECOG) performance status 0 or 1 who were older than 18 years of age, diagnosed with colorectal or gastric cancer and scheduled to receive oxaliplatin-based regimens (fluouracil, leucovarine and oxaliplatin, FLOX; 5-FU/leucovarine plus axaliplatine, FOLFOX; epirubicin, oxaliplatin and capecitabine EOX; and capecitabine plus oxaliplatin, XELOX). We excluded patients with a previous history of peripheral neuropathy or with symptomatic peripheral neuropathy at entry into the study. We also excluded patients who had received other chemotherapy regimens (except 5-fluorouracil alone) and those currently receiving gabapentin, carbamazepine, amitriptyline, amifostine or multivitamins. Both the study and the placebo group received calcium and magnesium supplements before and after oxaliplatin infusions. This supplementation consisted of calcium gluconate and magnesium sulfate, $1 \mathrm{~g}$ each, delivered intravenously over a 30-minute period just before the oxaliplatin infusion and repeated at the same dose after completion of the oxaliplatin infusion. Calcium gluconate and magnesium sulfate were given in the same infusion bag.

Patients were randomized five days before the beginning of the oxaliplatin treatment, to receive either vitamin $\mathrm{E}$ at a dose of $400 \mathrm{mg}$ daily or placebo, until after the end of the oxaliplatinbased chemotherapy regimen. Randomization was conducted by means of a sequence of consecutive random numbers that were distributed into consecutive envelopes. These were opened by the pharmacist (F.S.), who accordingly then allocated the patients either to placebo or to vitamin E. All other participants were blinded. Unblinding of the study allocation groups took place only after data-gathering for the study had been concluded, in order to enable analysis of the results.

We analyzed all the data using the intention-to-treat principle. We evaluated the intensity of the peripheral neuropathy using the Common Terminology Criteria for Adverse Events (CTCAE), version $3,{ }^{8}$ and specific gradation scales for oxaliplatin-induced peripheral neuropathy. ${ }^{9}$

Based on the $50 \%$ reduction in peripheral neuropathy associated with vitamin E prophylaxis that was observed in the study by Argyriou et al., ${ }^{5}$ we designed this study to detect a 50\% decrease in the incidence of peripheral neuropathy with a power of 0.8 and a type I error of 0.05 .

\section{RESULTS}

From October 2009 to November 2010, 38 patients were recruited into this study. We excluded four patients because of difficulties in contacting them by phone, loss from follow-up soon after entry into the study or missing information that precluded any further analysis. Of the 34 remaining patients, 18 patients were randomized to the vitamin $\mathrm{E}$ group and 16 to the placebo group. The patients' clinical characteristics are presented in Table 1.

Over the course of the study, $83 \%$ of the subjects in the vitamin E group developed peripheral neuropathy of grades $1 / 2$, versus $68 \%$ in the placebo group $(\mathrm{P}=0.45)$ (Figure 1). We observed a trend towards more diarrhea among patients who received vita$\min \mathrm{E}(55.6 \%$ versus $18.8 \%$; $\mathrm{P}=0.06)$. No other significant differences in toxicity were observed between the groups (Table 2). 


\section{DISCUSSION}

This was a small phase II randomized trial to determine whether vitamin E could prevent oxaliplatin-induced peripheral neuropathy, which can affect up to $80 \%$ of treated patients. ${ }^{1,10}$ Oxaliplatin is a very important medication for treating gastrointestinal malignancies, especially for colorectal, gastric and pancreatic cancers, but its use is often hampered by induction of severe and limiting peripheral neuropathy. ${ }^{11,12}$

Even though many attempts have been made to prevent this complication, including the use of magnesium and calcium infusions, ${ }^{13,14}$ oxcarbamazepine ${ }^{11}$ and antioxidants such as glutathione, ${ }^{7}$ peripheral neuropathy remains a challenge in treating these patients.

Vitamin E, which has antioxidant properties, has been studied in relation to prevention of cisplatin-induced peripheral neuropathy, with encouraging results. Therefore, we attempted to evaluate the use of vitamin $\mathrm{E}$ in the setting of oxaliplatin treatment.

We could not demonstrate any significant decrease in the incidence of acute oxaliplatin-induced peripheral neuropathy through vitamin $\mathrm{E}$ use. The small number of patients we enrolled might have prevented us from finding a smaller difference favoring vitamin $\mathrm{E}$ than the difference of $50 \%$ that we used in determining the number of patients to include in this trial. Moreover, the vitamin E dose that we used (400 mg) was less than that used by Argyriou (600 mg daily). ${ }^{5}$ However, Pace et al. ${ }^{4}$ reported results similar to those of Argyriou et al. ${ }^{5}$ with a dose of $400 \mathrm{mg}$ daily, which is the same dose as we used in this study. Furthermore, because we used calcium and magnesium supplementation in both groups, we cannot rule out the possibility that an interaction may have occurred between these supplements and the antioxidant activities of vitamin E, which may have

Table 1. Clinical characteristics of the patients included in this study

\begin{tabular}{|c|c|c|c|}
\hline Clinical characteristics & Vitamin E & Placebo & $P$ \\
\hline Age & $56(29-76)$ & $57(40-71)$ & \\
\hline \multicolumn{4}{|l|}{ Sex } \\
\hline Male & 10 & 8 & 0.70 \\
\hline Female & 8 & 8 & \\
\hline \multicolumn{4}{|c|}{ Eastern Cooperative Oncology Group (ECOG) } \\
\hline 0 & 15 & 14 & 0.73 \\
\hline 1 & 3 & 2 & \\
\hline \multicolumn{4}{|l|}{ Type of chemotherapy } \\
\hline FOLFOX & 9 & 7 & 0.93 \\
\hline FLOX & 5 & 5 & \\
\hline EOX & 4 & 4 & \\
\hline \multicolumn{4}{|l|}{ Primary tumor } \\
\hline Colon, adjuvant & 8 & 9 & 0.39 \\
\hline Colon, metastatic & 3 & 0 & \\
\hline Rectal & 3 & 3 & \\
\hline Advanced gastric & 4 & 4 & \\
\hline Radiotherapy & 2 & 3 & 0.53 \\
\hline Previous chemotherapy & 2 & 2 & 0.90 \\
\hline Diabetes & 2 & 0 & 0.16 \\
\hline Alcohol consumption & 2 & 4 & 0.29 \\
\hline
\end{tabular}

rendered vitamin $\mathrm{E}$ less effective for preventing peripheral neuropathy in our patients.

Recently, concordant with our findings, a study published by Kottschade et al. ${ }^{12}$ failed to show any significant reduction in the incidence of peripheral neuropathy in patients treated with neurotoxic chemotherapy, even with higher doses of vitamin E (400 mg twice a day). Their study also included 50 patients who received oxaliplatin. These authors observed that the incidence of neuropathy was $34 \%$ in vitamin E-treated patients and $29 \%$ in those who received placebo $(\mathrm{P}=0.43)$.

The main limitation of the present study was its size. In fact, this was a small randomized pilot clinical trial designed to exclude a $50 \%$ or higher difference between groups favoring vitamin E. Even though we cannot recommend vitamin E use on

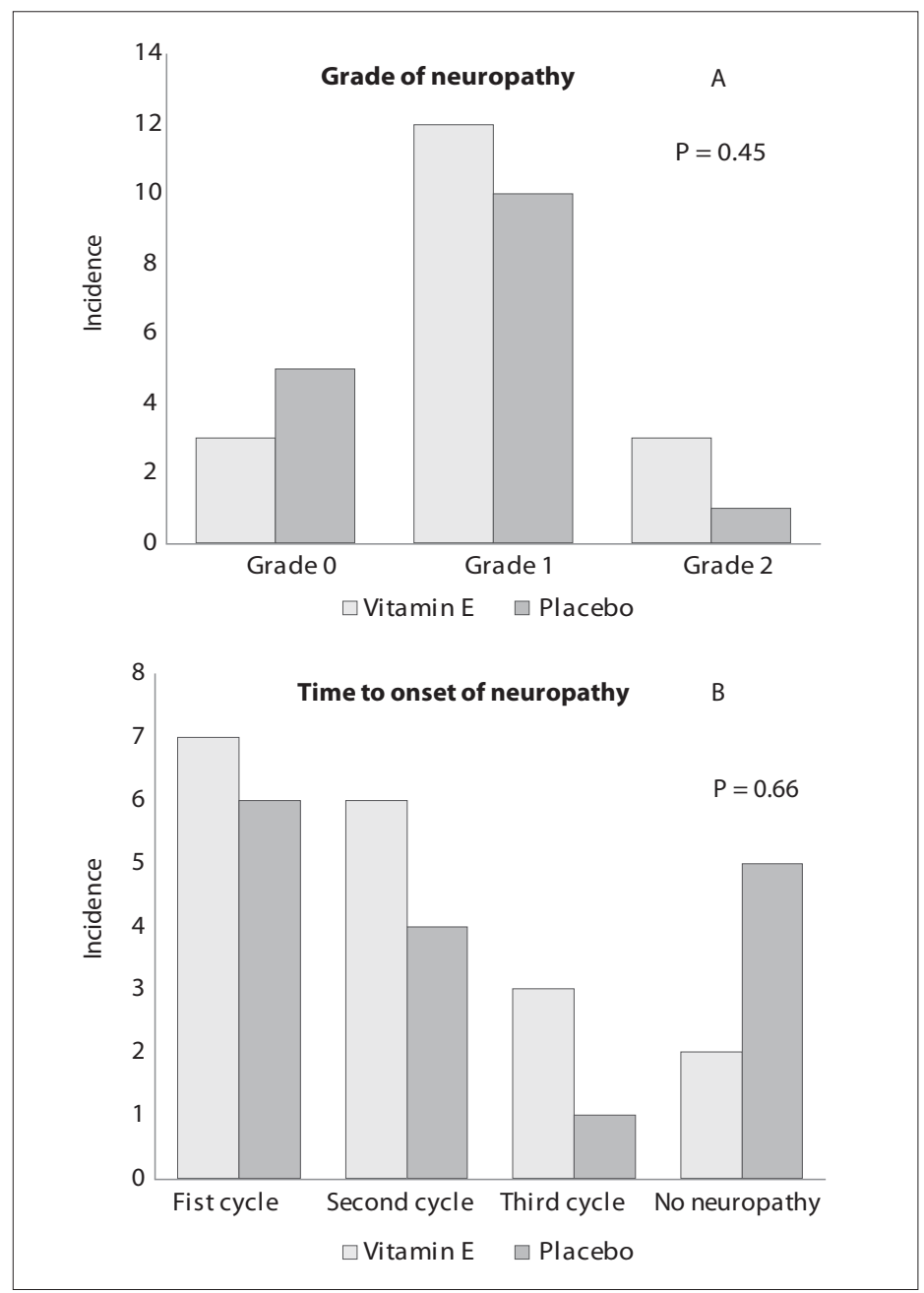

Figure 1. Cumulative number of peripheral neuropathy cases according to intensity, over the course of the chemotherapy treatment period (Graph A). Number of peripheral neuropathy cases according to the cycle of treatment in which they were first identified (Graph B). Grades defined in accordance with the Common Terminology Criteria for Adverse Events (CTCAE) version 3 and a specific gradation scale for oxaliplatin-induced peripheral neuropathy. 
Table 2. Toxicity observed during the study, according to the Common Terminology Criteria for Adverse Events (CTCAE) version 3 criteria

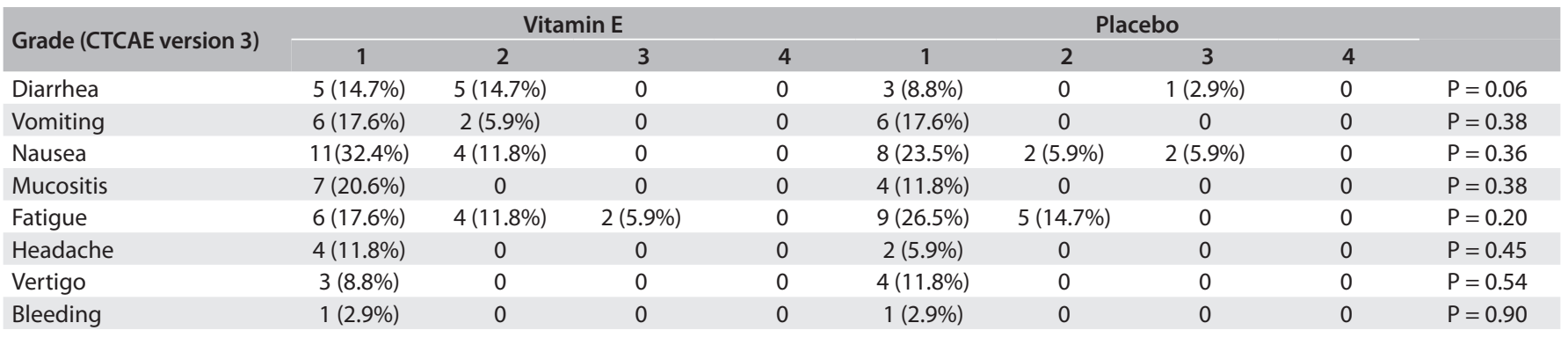

the basis of this small phase II pilot study, further work may be needed in this area in order to evaluate whether vitamin E may still have a role in this setting.

\section{CONCLUSION}

Based on the results from this study, we cannot recommend the use of vitamin $\mathrm{E}$ to prevent peripheral neuropathy in patients who are scheduled to receive oxaliplatin.

\section{REFERENCES}

1. Saif MW, Reardon J. Management of oxaliplatin-induced peripheral neuropathy. Ther Clin Risk Manag. 2005;1 (4):249-58.

2. Park SB, Goldstein D, Lin CS, et al. Acute abnormalities of sensory nerve function associated with oxaliplatin-induced neurotoxicity. J Clin Oncol. 2009;27(8):1243-9.

3. Gamelin L, Capitain O, Morel A, et al. Predictive factors of oxaliplatin neurotoxicity: the involvement of the oxalate outcome pathway. Clin Cancer Res. 2007;13(21):6359-68.

4. Pace A, Savarese A, Picardo M, et al. Neuroprotective effect of vitamin E supplementation in patients treated with cisplatin chemotherapy. J Clin Oncol. 2003;21(5):927-31.

5. Argyriou AA, Chroni E, Koutras A, et al. Vitamin Efor prophylaxis against chemotherapy-induced neuropathy: a randomized controlled trial. Neurology. 2005;64(1):26-31.

6. Argyriou AA, Chroni E, Koutras A, et al. A randomized controlled trial evaluating the efficacy and safety of vitamin E supplementation for protection against cisplatin-induced peripheral neuropathy: final results. Support Care Cancer. 2006;14(11):1134-40.

7. Cascinu S, Catalano V, Cordella L, et al. Neuroprotective effect of reduced glutathione on oxaliplatin-based chemotherapy in advanced colorectal cancer: a randomized, double-blind, placebocontrolled trial. J Clin Oncol. 2002;20(16):3478-83.

8. The National Cancer Institute. Common Terminology Criteria for Adverse Events v3.0 (CTCAE). Available from: http://www.eortc.be/ services/doc/ctc/ctcaev3.pdf. Accessed in 2012 (Apr 25).

9. Kautio AL, Haanpää M, Kautiainen $H$, et al. Oxaliplatin scale and National Cancer Institute-Common Toxicity Criteria in the assessment of chemotherapy-induced peripheral neuropathy. Anticancer Res. 2011;31(10):3493-6.
10. Grothey A. Clinical management of oxaliplatin-associated neurotoxicity. Clin Colorectal Cancer. 2005;5 Suppl 1:S38-46.

11. Argyriou AA, Chroni E, Polychronopoulos P, et al. Efficacy of oxcarbazepine for prophylaxis against cumulative oxaliplatin-induced neuropathy. Neurology. 2006;67(12):2253-5.

12. Kottschade LA, Sloan JA, Mazurczak MA, et al. The use of vitamin E for the prevention of chemotherapy-induced peripheral neuropathy: results of a randomized phase III clinical trial. Support Care Cancer. 2011;19(11):1769-77.

13. AndréT, Boni C, Navarro M, et al. Improved overall survival with oxaliplatin, fluorouracil, and leucovorin as adjuvant treatment in stage II or III colon cancer in the MOSAIC trial. J Clin Oncol. 2009;27(19):3109-16.

14. Nikcevich DA, Grothey A, Sloan JA, et al. Effect of intravenous calcium and magnesium (IV CaMg) on oxaliplatin-induced sensory neurotoxicity (sNT) in adjuvant colon cancer: Results of the phase III placebo-controlled, double-blind NCCTG trial N04C7. In: 2008 ASCO Annual Meeting; 2008. Available from: http://www.asco.org/ ASCOv2/Meetings/Abstracts?vmview=abst_detail_view\&conflD $=55$ \&abstract|D=32445. Accessed in 2012 (Apr 25).

The abstract of this paper was published online in conjunction with the ASCO 2011 Annual Meeting: J Clin Oncol 2011;29: (suppl; abstr e19505). Available from: http://www.asco.org/ascov2/Meetings/ Abstracts?\&vmview=abst_detail_view\&conflD=102\&abstract|D=77283. Acessed in 2012 (Jun 12).

Sources of funding: None Conflict of interest: None

Date of first submission: September 21, 2011

Last received: May 6, 2012

Accepted: June 12, 2012

\section{Address for correspondence:}

Auro Del Giglio

Rua Mariana Correia, 369

São Paulo (SP) - Brasil

CEP 01444-000

Tel. (+55 11) 4436-2094

E-mail: aurodelgiglio@gmail.com 